\title{
RAPID MEASURING PIPETTE.
}

BY EDWARD L, SMITH.

Recelved August 4, 8896.

THE apparatus described below is a device for rapidly measuring and discharging a definite volume of liquid. It may be well to state at this point that the principle is not applicable in all, or in even the majority of cases, where it is desired to measure and discharge liquid reagents in the laboratory. Where extreme accuracy is essential, the ordinary pipette or a burette must still be used. Perhaps the best way to explain the utility of the apparatus will be to state the exact use to which it is put

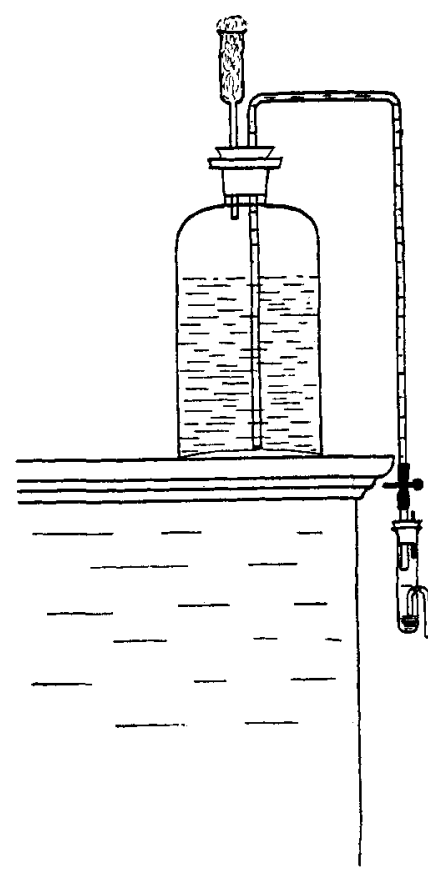

in our laboratory. In the course of some experiments with sand filters, samples of the different effluents as well as of the applied sewage were taken daily, treated with a small quantity of a concentrated sterilizing agent, and an analysis made each week of the combined daily samples.

It was to measure and discharge this sterilizing solution that the apparatus was devised. The quantity added in each case was five cc. Of course a variation from that amount of one- or two-tenths cc. would not materially affect the results and the great advantage in convenience and rapidity over the use of the common pipette for the same purpose is admitted by all who have seen the apparatus work. A large bottle forms the reservoir. The stopper of this bottle carries two tubes. One simply serves to admit air and contains a loose plug of cotton to exclude dust, etc. The other tube is bent to form an ordinary siphon and the end of the longer limb is attached to a short glass tube by means of a rubber connection, 
provided with a pinch-cock. The short glass tube to which reference was just made passes through a stopper inserted into the mouth of an ordinary test-tube. Through a hole blown in the side of this tube another glass tube, bent to form a siphon, is inserted and fastened in place by a piece of rubber tubing of the proper size, slipped on over the tube. The leg of the siphon inside the test-tube is of such a length that when the pinch-cock above is opened and the liquid allowed to enter the test-tube, five cc. will be automatically discharged when the level of the liquid has reached a mark on a line with the top of the bend in the siphon tube.

The apparatus can be constructed in a few moments in any laboratory, and for purposes to which it is adapted, it will, I am sure, be found satisfactory. It may be asked, what is the advantage of the form suggested over the ordinary burette with supply tubes? The answer is, it does away with the necessarily oft-repeated filling of the burette, and there is but one mark to watch in making the measurement-that previously mentioned, on the test-tube. The tubing used is of such size that a rapid discharge is insured, the time required being less than would be the case were a burette employed.

\section{MERCURIC CHLOROTHIOCYANATE.}

By Charies H. Herty AND J. G. SMith.

Received August 8, r8g6.

I T has been shown by one of us that the so-called compound lead iodochloride, $\mathrm{PbICl}$, is not a true chemical compound, but a mixture of lead iodide and lead chloride.

It has seemed advisable, therefore, to study more fully the nature of the compound mercuric chlorothiocyanate, $\mathrm{HgCl}$ (CNS), described by McMurtry. ${ }^{2}$ To this end a series of solutions was prepared, in one of which was used the exact proportions of mercuric thiocyanate and mercuric chloride given by McMurtry for the preparation of mercuric chlorothiocyanate; in the other members of the series, arbitrarily taken quantities of the one salt were replaced by equivalent quantities of the other. The

I Am. Chem.J., 18, 290.

$2 \mathrm{~J}$. chem. $50 \mathrm{c}, 1889,50$. 